\title{
THE BASIC PRINCIPLES OF FORMATION AND RECONSTRUCTION OF SCHOOL BUILDINGS IN THE CONDITIONS OF THE MODERN INFORMATION SOCIETY
}

\author{
Ekaterina Pozdnyakova ${ }^{1}$ Marina Zvjagintseva ${ }^{1}{\text { Andrey Pozdnyakov }{ }^{1 *} \text { Olga Barsova }}^{1}$ \\ ${ }^{1}$ Southwest State University, Faculty of Building and Architecture, Kursk, Russia
}

The article describes the process of transforming the industrial model of the school into a modern one. The conclusion is made about the influence of the development of the educational process on the formation of architecture and space-planning solutions of buildings. The increase in the nomenclature of classrooms is directly related to the complexity of the school structure and its functional component. Also, modern trends in the design of school buildings are described. The space of schools is considered as a multifaceted structure, combining both places for study and recreation. The problem of expanding and deepening the information space is analyzed, and ways of its solution are suggested. The main principles of designing public school zones, their division into different-scale volumes are described in detail. Conclusions are made about the requirements for modern school buildings to ensure their compliance with the aesthetic needs of the student's personality. The main problems that are present in the modern school fund are listed and possible options for its reconstruction are analyzed. Also, the principles of reconstruction in accordance with the types of planning organization are developed. Examples of solutions to some of these problems are given, and the issue of creating comfortable conditions for people with disabilities is singled out separately. The conclusion is made about the effectiveness of applying these principles to ensure the modern learning process.

Key words: Schools, Reconstruction, Building

\section{INTRODUCTION}

The existing system of modern society evolved in the historical process. As a shell of the educational process, the school building was transformed over time, depending on the requirements of the society.

The format of the first schools was a single room, where all age groups of students in all disciplines were trained. In connection with a small number of students, there was no need to differentiate the learning space and teaching methods for separate subjects. By the industrial period, the school is becoming an independent architectural object, when the need for literacy of the population has sharply increased. The volume of information has increased, the nomenclature of disciplines has also increased, that became the prerequisite for the formation of the objective method in the educational process and the most effective simultaneous training of more students within the framework of the class-lesson system [01]. To comply with this educational system, a clear division of the learning space is necessary. There are separate classes for different disciplines and groups of students at various levels. Classes in most cases are modular, and different disciplines are taught in a similar way.

Throughout the 20th century there was a quantitative change in the composition of premises in schools. With the increase in the volume of information, the number of classes for learning also increased. With the increase in the time spent by students in school, there appeared social functions: a place for eating, a place for physical activity, etc. [02].

The needs of modern society change the existing system of designing schools and form its current model. An important feature of the model of the modern society school is the diversity of the classroom composition. With a flexible and mobile approach to the learning process, modular classes cannot provide a full-fledged learning process. Variability, which has become an integral part of the educational process, also implies the possibility of modifying the learning space [03]. The increasing role of information and the need for its independent study form an extensive information zone in a school building with a function of constant free access.

\section{THE BASIC PRINCIPLES OF NEW SCHOOL BUILDINGS FORMATION}

The requirements of a modern information society to a person who interacts effectively with other people and is able to work in a team dictate the need for organizing a communicative space in the school building, that is the center of attraction for the entire school. The requirements to the aesthetic parameters of the school building are also increasing. The correspondence of public consciousness to the requirements of ecology provides for a more active inclusion of nature in the internal space of the building [04]. As the main activities that structure the social system develop, the amount of knowledge increases, and their range expands. In this regard, the learning process is 
complicated, differentiated, that leads to the transformation of the architectural and planning structure of the educational building (increasing the functional composition of the premises, complicating the planning organization).

To date, schooling is coming out of a rigid time-sharing framework for rest and learning and space (the constraints are framed by a typical class). The proposal to create transformable learning spaces in schools receives positive feedback from students and teachers. Some classes require the integration of classrooms - a single space, while the format provides for the partial fulfillment of the tasks by groups of students. Providing for the transformation of the premises, teachers receive a great variety of classes - the association of groups of students and their separation in the course of the lesson. Considering this aspect of training, classes of various capacities are required for conducting full-fledged classes.

If you initially design classes of different sizes, then the educational process becomes more flexible and mobile, it is these principles that the learning space has to answer. Some of the classrooms should be able to transform: the union of several classes into a single space or, on the contrary, the separation of one class into independent parts.

At the design stage, it is possible to envisage the possibility of transforming not only the educational premises, but also the public zone. In addition, it is necessary to transform and open communication spaces in a more isolated room. You can change the sports space - from the main premises of the gym for physical education classes, you can separate isolated sports zones. For the separation of quiet rest from active leisure it is possible to provide for a temporary separation of game zones in recreation or mini sports zones.

The principle of the transformed room can also be successfully applied for primary school. For schoolchildren of primary school age, there is a need for a succession of educational and play activities. In addition, in primary schools it is desirable to provide facilities for an extended day, that is, with the possibility of a quiet rest. The presence of transformed rooms allows combining the game and the study space; therefore, using more rationally the training areas [05]. The use of various partitions will allow organizing a flexible mobile space in the school building. In this case the partitions can be: horizontal, vertical, with manual or mechanical drive, with top or bottom suspension. Types of materials used can be different: wooden, roll of various special fabrics or synthetic materials (non-flammable), conjugated with elements of metal structures, with layers of special acoustic materials, etc. [02].

Deepening and expanding the information space requires open access to information resources. At the moment, many schools have a library with a reading room. In most cases, the reading room is designed for 10 - 15 students, and the room whe-re the library is located, as a rule, is placed in the peripheral zone. During the break the stu- dents have time to walk, take the necessary literature and return to the office. Thus, access to library resources is very conditional. To provide modern students with open access to information resources, it is necessary to deduce a part of the library fund in recreational spaces, equipping places for visitors and supplementing them with computers with access to the Internet. Such so-called information sites can be several, necessarily located in the zone of five-minute accessibility of the maximum number of schoolchildren [06].

In the case of using the centric scheme in the planning decision of the school building, providing step-by-step accessibility to the information zone becomes a simple task if it is included in the central space. When using the blocked type of planning solutions, it becomes necessary to include small areas (up to 6-8 sq. m.) with information resources into the main training blocks.

With a flexible schedule, it is also possible to conduct classes not with the whole class, but with a group of students. And not only during the lesson, but also, for example, during the prolongation or in the independent work of a group of schoolchildren, in group work, etc. In this regard, there should be places for small groups of 4 - 10 people. An example can be specially provided places in recreation or part of the class separating the partition. In any case, it is important to create a perception of visual separation from the common space. There are a lot of options here: low partitions, podiums, arbors, grottos. The area of these zones is $3-6$ sq. $m$.

An open public communication space is also needed in the modern school. At school, the child not only receives knowledge and spends about ten years of his life, but also develops by associating with the society. In the modern information society there is a need for socialization, which means that communication skills should be taught in the school. The space where every school stream will intersect daily, being a meeting place not only with peers, but also with classmates, gradually helps the child to realize that he is an integral part of a large community.

The atrium, the vast entrance junction or the presence of a large pocket in recreation are the options for making public communicative space. It should be saturated with other functions, one or more. A possible option here may be an information zone where you can obtain the necessary materials from library sources or freely available through the network. In public space, there may also be places for quiet rest or small cafes. If the principle of transformation is observed with the possibility of organizing closed sections, it can be used as an assembly hall. You can organize concerts or performances for a group of students, arrange meetings for the whole school, etc. The combination of public space with a green zone makes it informal and as comfortable as possible [07].

In connection with the fact that the main function of the school is becoming socializing, not educational, 
the ratio of public and educational premises is drastically changing. In existing schools, the number of classrooms (classes, classrooms, laboratories) reaches $80 \%$. In modern conditions, a school is required, the ratio of areas in which preferably the following: $50 \%$ directly to study rooms, $50 \%$ of public facilities. Entering the public space in the form of an information zone, as places for creative work in small groups, the educational function takes $10-20 \%$ of it. That is, due to the so-called "soft", indirect learning, students are oriented toward self-education.

According to the wishes of teachers, there is already a need to provide classes of different volumes not only in capacity, but also in configuration, changing the existing system of rectangular shape. In classes, it is possible to provide places for storing individual things of students, provide for lecture-oriented lecture-rooms, etc. In any case, before designing a new school or reconstructing an existing school, it is necessary to take into account the wishes of the teaching staff of a particular school for the capacity and configuration of classes. Applying the principle of multi-scale zoning and public and educational space, it is necessary to avoid monotony.

For individual rest and communication in small groups, it is necessary to provide for private zones. They can be self-contained semi-closed structures of small volume, separated by a partition or a group of upholstered furniture, dotted into the common space. Maximum use of the window space makes it possible to use it as a place for rest.

Public space also needs visual division into smaller components in size, that is, it should not just be a large room of considerable volume. Complex relief and configuration, location in different levels are the distinctive features of the social and communicative space.

\section{DIRECTIONS FOR RECONSTRUCTION}

Based on the principles of the new school building, the ways and directions for reconstructing the existing school fund are defined: reorganization of the corridor system into a system of educational and public premises united by a public communicative space; creation of conditions for free access to information at any time; including classes of larger and smaller volumes than existing ones; integration of natural elements into the internal space of the school building; creation of conditions for school attendance by children with disabilities.

For the reconstruction of school buildings, it is necessary to take into account the main problems of the existing school fund and its inconsistency with expectations and ideas about the new structure of the school. It should be noted that the reconstruction of school buildings cannot go only on the principle of altering one premise to another, since there is a high probability that you will have to sacrifice individual rooms and classes for organizing an effective public and educational space. All this reduces the economic effect, but increases the social. It is also necessary to increase the additional volumes.

First and foremost, it is important to get rid of the corridor system by breaking long narrow communications with the insertions of public space. In this case, some of the classes will be lost. Some classes will change their configuration and volume. It is necessary to think over the system of uniting / disconnecting the cabinets, the system of mobile partitions between the educational premises in order for teachers to be able to organize the educational process in accordance with the specifics of the academic discipline [06].

The big problem with many existing schools is the organization of the entrance node. Often, the lobby is a fragment of the communicative corridor and does not give an idea of the flows and main directions in the building. In this regard, it is necessary to redesign the input nodes, expand the window openings, perhaps an extension to increase the area of the hall. If possible, organize a mini-office in the lobby to receive the necessary information by visitors and schoolchildren [08].

A complex task in the reconstruction is the creation of a communicative public space because of the saving of areas during construction. Creating a large hall by removing a number of classes is not possible because of the low height of the standard floor. The room will be disproportionate. The most likely is the possibility of a large room creating by the partial removal of the recreation of one of the floors.

Much attention in the reconstruction should be given to creating comfortable conditions for people with disabilities. It is necessary to provide not only ramps at the entrance to the school, but also elevators.

Considering the issue of reconstruction separately for each type of planning organization of the school building, it can be noted that the "centric" type most fully meets the new design principles and can be subject to only a small adjustment. Typically, for this type of organization is characteristic of the educational process around the public zone of a particular purpose. In the process of reconstruction, it is necessary to clarify the purpose of the public space, to consider the possibility of including active recreation areas and the information zone in the learning space with the distance of the learning space, and also to provide a variety of study rooms by volume and configuration [09].

The "linear" type is convenient for isolating the primary school into a separate unit that does not intersect with other age groups. At the same time, each age group has free access to public areas.

The "blocked" type of planning organization of a school building as a whole is close to "centric", uniting around several small centers. Requires mainly adjusting the volume and configuration of the classrooms.

The "trunk" type is the most common type in the Russian school fund. It requires maximum redevelopment to meet 
modern standards. The main task is the formation of a public open access center, the creation of an accessible information zone, and the organization of a convenient input node. It is also necessary, as in all other cases, to change the configuration of the classrooms, to lay the possibility of transformation into the learning space [06].

\section{CONCLUSION}

The most important aspect in designing new or renovating existing public school buildings is the social effect, not the economic one. If we consider the school from this point of view, the overexpenditure of areas and materials becomes justified. To match the modern school with the aesthetic needs of the information society person, it is necessary to project a rhythmic, multi-scale space, devoid of monotony. The layout should have a dynamic rhythmic grid, with the complication of the elements. To create a psychologically comfortable atmosphere, it is necessary to envisage the integration of natural elements into the internal space of the school. The use of these principles by the architect-designer during the design will create a modern school building that meets the requirements of all participants in the educational process.

\section{ACKNOWLEDGEMENT}

Author thanks the Rector of the Southwest State University, Doctor of Technical Sciences Yemelyanov S.G.

\section{REFERENCES}

1. Savarenskaya, T.F. (2006) History of town-planning art, $375 \mathrm{p}$.

2. Pozdnyakova, E.V., Zvyagintseva, M.M., Pozdnyakov, A.L. (2016) Peculiarities of organization of the volume-planning structure of school buildings (Russian experience): Proceedings of the Southwest State University, №4 (67), pp. 87-96.

3. Bunik, O.A. (2007) Architectural methods of modernization of general education schools and their systems in the structure of a large city: research and recommendations on the example of Yaroslavl: Dis. Cand. Architecture, $214 \mathrm{p}$.

4. Slavyanskiy, S.P. (2007) Systems and types of buildings of general education schools in the structure of a large city: research and recommendations on the example of Veliky Novgorod: Dis. Cand. Architecture, $178 \mathrm{p}$.

5. Khokhlova, V.V. (2002) Sociocultural interaction of the subjects of the educational space in the information society: dis. Cand. Sociology. Sciences, 403 p.

6. Pozdnyakova, E.V., Pozdnyakov, A.L., Barsova, O.Yu., (2016) Principles of reconstruction of the existing school fund: the Science of Young - the Future of Russia: a collection of scientific articles of the International Scientific Conference of Advanced Developments of Young Scientists, pp. 84-87.
7. Pimenova, E.V. (2003) Methodical foundations of architectural and planning reconstruction of the school fund: research and recommendations on the example of the city of Rostov-on-Don, $159 \mathrm{p}$.

8. Pozdnyakova, E.V., Pozdnyakov, A.L. (2016) Modern tendencies of building designing of educational institutions on the example of schools: The Science of Young - the Future of Russia: a collection of scientific articles of the International Scientific Conference of Advanced Developments of Young Scientists, pp. 80-84.

9. Pozdnyakova, E.V. (2016) A comparative survey of architecturally and space-planning solutions of school buildings in the industrial and modern information society: The Science of Young - the Future of Russia: a collection of scientific articles of the International Scientific Conference of Advanced Developments for Young Scientists, pp. 77-80.
Paper submitted: 26.07.2017.

Paper accepted 21.09.2017.

This is an open access article distributed under the CC BY-NC-ND 4.0 terms and conditions. 